\title{
Frustrated Lewis Pair Stabilized Phosphoryl Nitride (NPO), a Mono Phosphorus Analogue of Nitrous Oxide $\left(\mathrm{N}_{2} \mathrm{O}\right)$
}

André K. Eckhardt, Martin-Louis Y. Riu, Peter Müller and Christopher C. Cummins*

Department of Chemistry, Massachusetts Institute of Technology, Cambridge MA, USA; ccummins@mit.edu

Keywords: Azides - Frustrated Lewis Pairs - Photochemistry - Small Molecule Activation Staudinger Reaction

\begin{abstract}
Phosphoryl nitride (NPO) is a highly reactive intermediate, and its chemistry has only been explored under matrix isolation conditions so far. Here we report the synthesis of an anthracene (A) and phosphoryl azide-based molecule $\left(\mathrm{N}_{3} \mathrm{P}(\mathrm{O}) \mathbf{A}\right)$ that acts as a molecular synthon of NPO. Experimentally, $\mathrm{N}_{3} \mathrm{P}(\mathrm{O}) \mathbf{A}$ dissociates thermally with a first order kinetic halflife that is associated with an activation enthalpy of $\Delta H^{\ddagger}=27.5 \pm 0.3 \mathrm{kcal} \mathrm{mol}^{-1}$ and an activation entropy of $\Delta S^{\ddagger}=10.6 \pm 0.3 \mathrm{cal} \mathrm{mol}^{-1} \mathrm{~K}^{-1}$ that are in good agreement with calculated DLPNO-CCSD(T)/cc-pVTZ//PBE0-D3(BJ)/cc-pVTZ energies. In solution $\mathrm{N}_{3} \mathrm{P}(\mathrm{O}) \mathbf{A}$ undergoes Staudinger reactivity with tricyclohexylphosphine $\left(\mathrm{PCy}_{3}\right)$ and subsequent

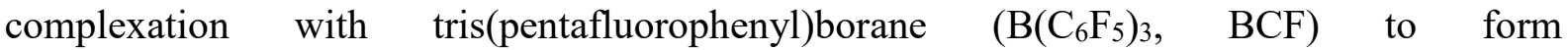
$\mathrm{Cy}_{3} \mathrm{P}-\mathrm{NP}(\mathrm{A}) \mathrm{O}-\mathrm{B}\left(\mathrm{C}_{6} \mathrm{~F}_{5}\right)_{3}$. Anthracene is cleaved off photochemically to form the frustrated Lewis pair (FLP) stabilized NPO complex $\mathrm{Cy}_{3} \mathrm{P} \oplus_{-} \mathrm{N}=\mathrm{P}-\mathrm{O}-\mathrm{B} \ominus\left(\mathrm{C}_{6} \mathrm{~F}_{5}\right)_{3}$. Intrinsic Bond Orbital (IBO) analysis suggests that the adduct is zwitterionic, with a positive and negative charge localized on the complexing $\mathrm{Cy}_{3} \mathrm{P}$ and $\mathrm{BCF}$, respectively.
\end{abstract}

Phosphoryl nitride is the mono phosphorus analogue of well-known and studied nitrous oxide $\left(\mathrm{N}_{2} \mathrm{O}\right)$, a naturally abundant gas that has been recognized as the dominant ozone-depleting substance in the Earth's stratosphere emitted in the $21^{\text {st }}$ Century. ${ }^{1}$ In chemical transformations $\mathrm{N}_{2} \mathrm{O}$ is primarily used as a powerful oxidant, as it is a poor ligand to transition metals due to its weak $\sigma$-donating and $\pi$-accepting capabilities. ${ }^{2}$ Nitrous oxide has been shown to coordinate to transition metal center in an end-on, as well as side-on, fashion. ${ }^{3-11}$ Additionally, nitrous oxide easily forms stable complexes with frustrated Lewis pairs (FLPs) and N-heterocyclic carbenes (NHCs) under mild conditions. ${ }^{12-14}$

In contrast, little is known about the chemistry of linear two-fold coordinated phosphorus (V) NPO due to the lack of a suitable molecular precursor that releases the molecule under mild reaction conditions. Phosphoryl nitride was first generated 10 years ago via the irradiation of explosive phosphoryl triazide $\left(\mathrm{O}=\mathrm{P}\left(\mathrm{N}_{3}\right)_{3}\right)^{15-17}$ and characterized under cryogenic matric isolation conditions. ${ }^{18-19}$ Phosphoryl nitride undergoes photochemically induced isomerizations to PNO and cyclic PON (Figure 1) and reversibly combines with carbon monoxide. ${ }^{18-19}$ On the other hand, the phosphorus(III) isomer PON has been known since 1988 and was formed after photolysis of an $\mathrm{O}_{3} / \mathrm{PN}$ mixture diluted in solid argon under cryogenic 
matrix isolation conditions. ${ }^{20}$ Interestingly, NPO was not observed in this experiment. In later experiments, namely gas-phase IR laser absorption spectroscopy of $\mathrm{NO} / \mathrm{P}_{4} / \mathrm{O}_{2} /$ noble-gas mixtures $^{21}$ and a microwave spectroscopic study of a dc glow discharge of $\mathrm{NO} / \mathrm{H}_{2}$ over red phosphorus, ${ }^{22}$ there was also no experimental evidence for NPO. This is surprising given a recent high-level electronic structure focal point analysis suggesting that NPO is energetically preferred by $1.87 \mathrm{kcal} \mathrm{mol}^{-1}$ over PNO. ${ }^{23}$ The Lewis structures of NPO and PNO are best described with formal charges rather than the neutral $\mathrm{N} \equiv \mathrm{P}=\mathrm{O}$ form (Figure 1). ${ }^{18,24-25}$ Related NPS isomers can be prepared in a similar fashion from thiophosphoryl azide $\left(\mathrm{S}=\mathrm{P}\left(\mathrm{N}_{3}\right)_{3}\right)$ via photolysis or high-vacuum flash pyrolysis (HVFP). ${ }^{26}$ In the HVFP experiments the neutral five-membered sulfur-pnictogen(III) ring $\mathrm{SN}_{2} \mathrm{P}_{2}$ was also identified under the pyrolysis products, suggesting head-to-tail dimerization of SNP and subsequent elimination of a sulfur atom. $^{27}$ In the solid state, a material of the composition NPO is known to exist in both a $\beta$-cristobalite and a slightly thermodynamically less stable amorphous form. ${ }^{28}$ Furthermore, isomers of NPO and NPS are also considered potential interstellar molecules, ${ }^{18,23-24}$ given the presence of $\mathrm{PN}$ in interstellar media. ${ }^{29-30}$

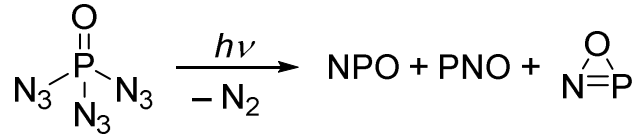

$$
\begin{aligned}
& \stackrel{\ominus}{\mathrm{O}}-\stackrel{\oplus}{\mathrm{P}} \equiv \mathrm{N} \longleftrightarrow \mathrm{O}=\mathrm{P} \equiv \mathrm{N} \longleftrightarrow \mathrm{O}=\stackrel{\oplus}{\mathrm{P}}=\stackrel{\ominus}{\mathrm{N}}
\end{aligned}
$$

Figure 1: Top: Photochemical formation of all three NPO isomers. Bottom: Lewis structures of NPO.

Dibenzo- $7 \lambda^{3}$-phosphanorbornadiene derivatives have served as suitable precursors to phosphorous bearing small molecules of interstellar interest. ${ }^{31-34}$ We reported recently the synthesis of an anthracene-based azido phosphine $\left(\mathrm{N}_{3} \mathrm{PA}\right)$ that releases molecular $\mathrm{PN}$ in solution and shown to transfer PN to an iron complex under mild conditions. ${ }^{35}$ Here we report the oxidation of $\mathrm{N}_{3} \mathrm{PA}$ to anthracene-based phosphoryl azide $\left(\mathrm{N}_{3} \mathrm{P}(\mathrm{O}) \mathbf{A}\right.$, Figure 2). Given the poor thermal stability of $\mathrm{N}_{3} \mathrm{PA}$ at room temperature $\left(t_{1 / 2}=29.1 \pm 1.6 \mathrm{~min}\right)$ we selected $2,4,6$ trimethylbenzonitrile $\mathrm{N}$-oxide (MesCNO) as a fast and effective oxygen atom transfer (OAT) reagent. $^{36}$ Inside the glovebox $\mathrm{N}_{3} \mathrm{PA}$ and MesCNO were dissolved in a minimal amount of diethyl ether and tetrahydrofuran (4:1 ratio) and stirred under foil in the dark. After half an hour hexanes was added to the reaction mixture and the slurry was cooled to $-20{ }^{\circ} \mathrm{C}$ to precipitate out the product. After half an hour the colorless precipitate was collected by vacuum filtration, washed with a minimal amount of pentane and dried under the nitrogen atmosphere of the glovebox providing up to $74 \%$ clean product. Single crystals of $\mathrm{N}_{3} \mathrm{P}(\mathrm{O}) \mathbf{A}$ grown from diethyl ether at $-20{ }^{\circ} \mathrm{C}$ were characterized in a single crystal X-ray diffraction experiment and the molecular structure is depicted in Figure 2 (see also Table S3). The structure is in line with strong infrared bands for the azide group at 2154 and $2141 \mathrm{~cm}^{-1}$ (Figure S4) as well as a single resonance in the ${ }^{31} \mathrm{P}$ NMR spectrum at $\delta 75.9 \mathrm{ppm}\left(\mathrm{t},{ }^{2} J_{\mathrm{PH}}=11.1 \mathrm{~Hz}\right.$; Figure S3). 

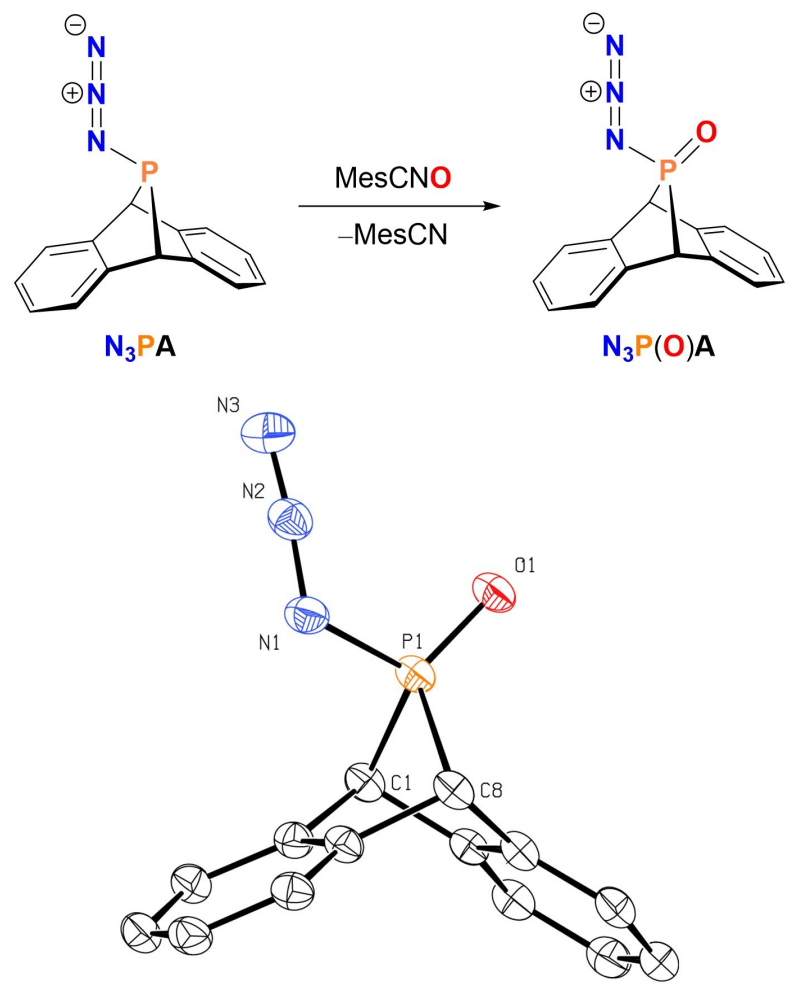

Figure 2: Top: Synthesis of $\mathrm{N}_{3} \mathrm{P}(\mathrm{O}) \mathrm{A}$ using mesityl nitrile oxide (MesCNO) as an OAT reagent. Bottom: Molecular structure of $\mathrm{N}_{3} \mathrm{P}(\mathrm{O}) \mathrm{A}$ with thermal ellipsoids shown at the $50 \%$ probability level. Hydrogen atoms are omitted for the sake of clarity. Selected interatomic distances $(\AA)$ : P1-N1, 1.7066(17); P1-O1, 1.4754(13); $\mathrm{P} 1-\mathrm{C} 1,1.8520(19) ; \mathrm{P} 1-\mathrm{C} 8,1.861(2) ; \mathrm{N} 1-\mathrm{N} 2,1.243(2)$; and N2-N3, 1.128(3). Selected interatomic bond angles $\left.{ }^{\circ}\right)$ : C1-P1-C8, 83.51(9); N1-P1-O1, 111.61(8) and P1-N1-N2, 115.09(13).

$\mathrm{N}_{3} \mathrm{P}(\mathrm{O}) \mathrm{A}$ was heated under vacuum and the release of molecules into the gas phase was monitored by mass spectrometry using a molecular-beam mass spectrometer (MBMS). We observed a strong increase in signals for $\mathrm{N}_{2}{ }^{+}(m / z=28), \mathrm{P}^{+}(m / z=31), \mathrm{PN}^{+}(m / z=45)$, and $\mathbf{A}^{+}$ $\left(\mathrm{m} / \mathrm{z}=178\right.$ and smaller fragments) starting at around $60^{\circ} \mathrm{C}$ in the chromatogram. Additionally, a signal for $m / z=59$ was observed that may originate from isomers of $\mathrm{CPO}^{+}$or $\mathrm{PN}_{2}{ }^{+}$. However, no signal at $m / z=61$ for any NPO isomer was observed. Even reducing the voltage from 70 to $35 \mathrm{~V}$ in the electron impact ion source did not lead to the detection of any new signal for $m / z=61$. Consistent with the observed decomposition at $60^{\circ} \mathrm{C}$ in the MBMS experiment, solid $\mathrm{N}_{3} \mathrm{P}(\mathrm{O}) \mathrm{A}$ melts at $45{ }^{\circ} \mathrm{C}$ and forms a red-brown solid at $60{ }^{\circ} \mathrm{C}$.

In solution $\mathrm{N}_{3} \mathrm{P}(\mathrm{O}) \mathrm{A}$ decomposes upon either thermal or photochemical activation. After $1 \mathrm{~h}$ irradiation of a quartz NMR tube containing a solution of $\mathrm{N}_{3} \mathrm{P}(\mathrm{O}) \mathbf{A}$ in benzene- $d_{6}$ at $\lambda=254$ $\mathrm{nm}$ only resonances of $\mathbf{A}$ could be detected in the ${ }^{1} \mathrm{H}$ NMR spectrum and no resonances were observed in the ${ }^{31} \mathrm{P}$ spectrum. Heating $\mathrm{N}_{3} \mathrm{P}(\mathrm{O}) \mathbf{A}$ at $80{ }^{\circ} \mathrm{C}$ in benzene- $d_{6}$ for 30 min results in the observation of signals of $\mathbf{A}$ in the ${ }^{1} \mathrm{H}$ NMR spectrum as well as one major resonance at $\delta$ $112.7 \mathrm{ppm}$ in the ${ }^{31} \mathrm{P}\left\{{ }^{1} \mathrm{H}\right\}$ spectrum together with some other minor resonances (Figure S5). However, none of these resonances could be unambiguously assigned. We followed the thermal decay of $\mathrm{N}_{3} \mathrm{P}(\mathrm{O}) \mathrm{A}$ in benzene- $d_{6}$ by ${ }^{1} \mathrm{H}$ NMR spectroscopy (Figure S20-S22, Table S1S2) and found that the azide decomposes at $52.5^{\circ} \mathrm{C}$ with a first-order kinetics half-life of around half an hour $\left(t_{1 / 2}=25.5 \pm 0.4 \mathrm{~min}\right)$. Further kinetic measurements on $\mathrm{N}_{3} \mathrm{P}(\mathrm{O})$ A decomposition were performed over the temperature range of $52.5-70.0^{\circ} \mathrm{C}$. An Eyring analysis revealed activation parameters of $\Delta H^{\ddagger}=27.5 \pm 0.3 \mathrm{kcal} \mathrm{mol}^{-1}$ and $\Delta S^{\ddagger}=10.6 \pm 0.3 \mathrm{cal} \mathrm{mol}^{-1} \mathrm{~K}^{-1}$ (Figure 
S22). The first-order behavior is indicative of a unimolecular rate-determining step, consistent with fragmentation of $\mathrm{N}_{3} \mathrm{P}(\mathrm{O}) \mathbf{A}$ into $\mathbf{A}$ and presumably a $\mathrm{O}=\mathrm{PN}_{3}$ fragment (vide infra).

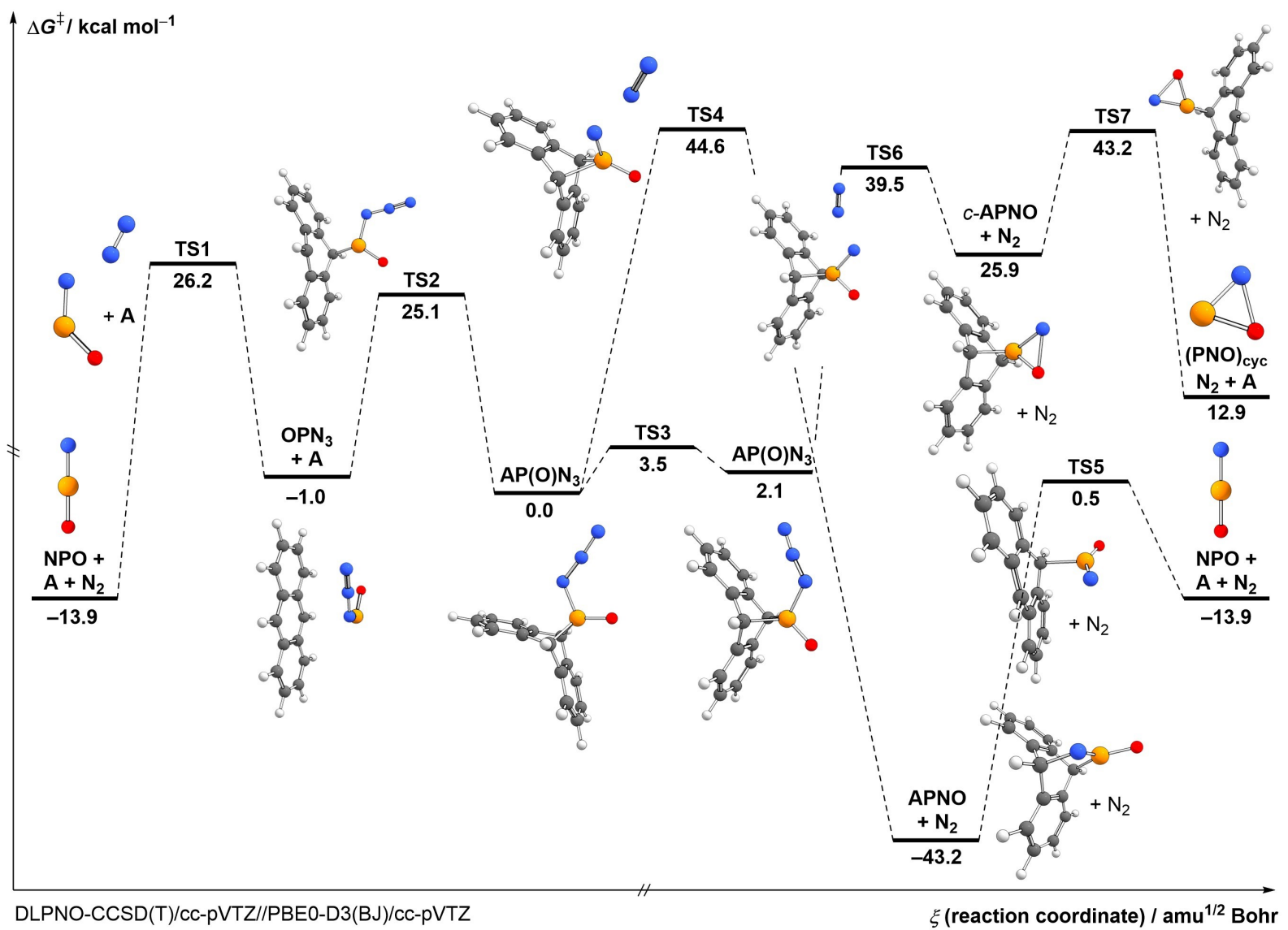

Figure 3: $\mathrm{N}_{3} \mathrm{P}(\mathrm{O})$ A decomposes into $\mathrm{N}_{2}$, cyclic and linear NPO isomers, and anthracene (A) either by dinitrogen and subsequent anthracene loss or via anthracene loss and further dissociation of the $\mathrm{OPN}_{3}$ fragment into NPO and $\mathrm{N}_{2}$. The latter pathway is energetically preferred. Gibbs free energy values are computed for $T=298.15 \mathrm{~K}$. Color code: carbon $=$ grey, hydrogen $=$ white, nitrogen $=$ blue, phosphorus $=$ orange, oxygen $=$ red .

We computed the most essential part of the potential energy surface around $\mathrm{N}_{3} \mathrm{P}(\mathrm{O}) \mathrm{A}$ at PBE0-D3(BJ)/cc-pVTZ + Gibbs free energy correction with augmented DLPNO-CCSD(T)/cc-pVTZ single point energies (Figure 3). Similar as in our previous study of $\mathrm{N}_{3} \mathrm{PA},{ }^{35}$ we located two minima for $\mathrm{N}_{3} \mathrm{P}(\mathrm{O}) \mathbf{A}$, and the energetically preferred conformer is in line with our crystal structure depicted in Figure 2. In the higher energy conformer, the $\mathrm{P}-$ $\mathrm{N}$ single bond is rotated by $180^{\circ}$ and the azide group takes a parallel position to a terminal aromatic ring that results in an energy rise of $2.1 \mathrm{kcal} \mathrm{mol}^{-1}$. Both conformers are connected by a low lying transition state $\mathbf{T S 3}\left(3.5 \mathrm{kcal} \mathrm{mol}^{-1}\right)$. For the fragmentation of $\mathrm{N}_{3} \mathrm{P}(\mathrm{O}) \mathbf{A}$, we initially considered cleavage of dinitrogen from the azide group. For each of the two $\mathrm{N}_{3} \mathrm{P}(\mathrm{O}) \mathbf{A}$ conformers, we located, in contrast to $\mathrm{N}_{3} \mathrm{PA}$, an energetically high lying transition state (TS4 $\left(44.6 \mathrm{kcal} \mathrm{mol}^{-1}\right)$ and TS6 $\left.\left(39.5 \mathrm{kcal} \mathrm{mol}^{-1}\right)\right)$ that is associated with dinitrogen loss and a ring expansion to form tricyclic APNO in a highly exothermic $\left(-43.2 \mathrm{kcal} \mathrm{mol}^{-1}\right)$ and cyclic NPO attached to anthracene (c-APNO) in a highly endothermic $\left(25.9 \mathrm{kcal} \mathrm{mol}^{-1}\right)$ reaction, respectively. The dissociation reactions are completed with anthracene loss to form linear NPO via TS5 (43.7 kcal mol ${ }^{-1}$ barrier) and cyclic NPO via TS7 (17.3 kcal mol ${ }^{-1}$ barrier). However, in general these high reaction barriers cannot be overcome by simple heating at $80{ }^{\circ} \mathrm{C}$. Therefore, we investigated a second dissociation pathway that is initiated by the cleavage of anthracene. We located a concerted transition state TS2 that is associated with a reaction barrier 
of $25.2 \mathrm{kcal} \mathrm{mol}^{-1}$, leading to the fragmentation of $\mathrm{N}_{3} \mathrm{P}(\mathrm{O}) \mathbf{A}$ into $\mathbf{A}$ and $\mathrm{OPN}_{3}$. These calculations also suggest that the latter fragment eliminates $\mathrm{N}_{2}$ via TS1 $\left(26.2 \mathrm{kcal} \mathrm{mol}^{-1}\right)$ to form linear NPO. Based on the computed free energy values involving the elimination of $\mathbf{A}$ in the first step is energetically favored. The pathway via TS2 with a total barrier of $25.1 \mathrm{kcal}$ $\mathrm{mol}^{-1}$ is in good agreement with the experimental value of our Eyring analysis $\left(\Delta G^{\ddagger}=\Delta H^{\ddagger}-\right.$ $T \Delta S^{\ddagger}=24.4 \pm 0.1 \mathrm{kcal} \mathrm{mol}^{-1}$ at $\left.298.15 \mathrm{~K}\right)$. However, the fate of the $\mathrm{OPN}_{3}$ fragment remains unclear. The experimentally observed resonance at $\delta 112.7 \mathrm{ppm}$ in the ${ }^{31} \mathrm{P}\left\{{ }^{1} \mathrm{H}\right\}$ after thermolysis cannot be assigned to the $\mathrm{OPN}_{3}$ fragment or the NPO molecule.

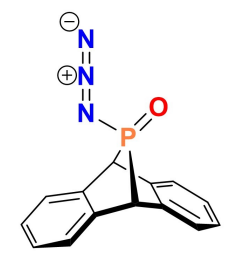

$\mathrm{N}_{3} \mathrm{P}(\mathrm{O}) \mathrm{A}$

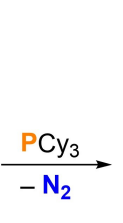

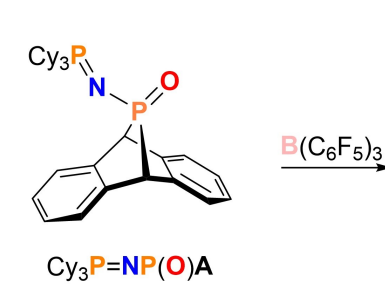

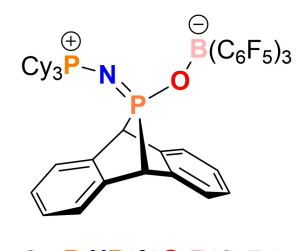

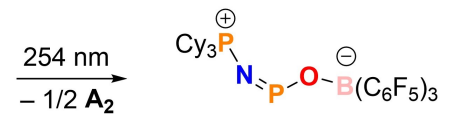

$$
\begin{aligned}
& \mathrm{CY}_{3} \mathrm{P}-\mathrm{NPO}-\mathrm{B}\left(\mathrm{C}_{6} \mathrm{~F}_{5}\right)_{3}
\end{aligned}
$$$$
\mathrm{Cy}_{3} \mathrm{P}-\mathrm{NP}(\mathbf{A}) \mathrm{O}-\mathrm{B}\left(\mathrm{C}_{6} \mathrm{~F}_{5}\right)_{3}
$$
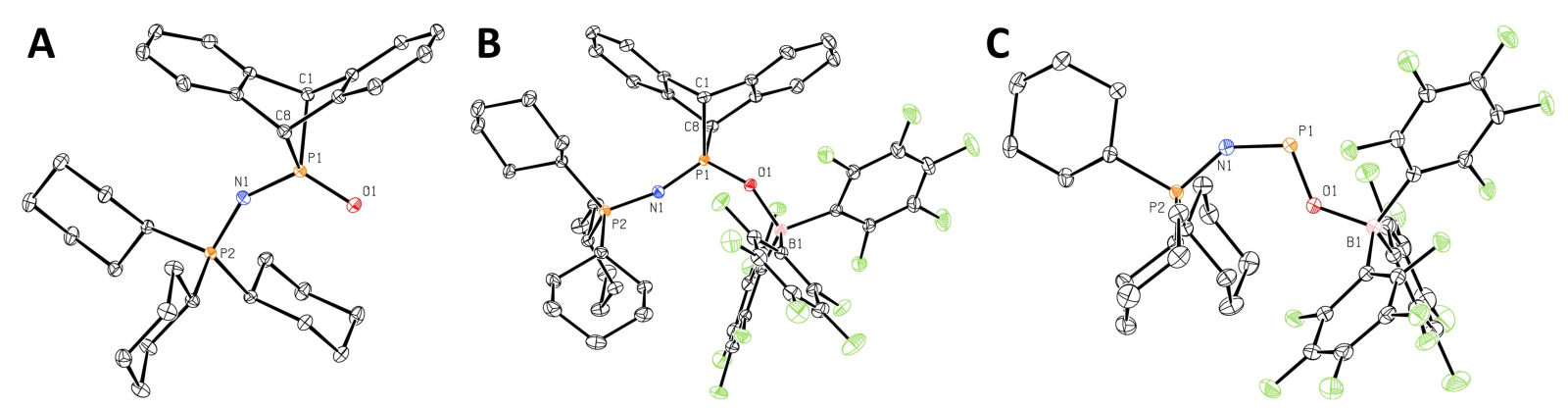

Figure 4: Top: Synthesis of $\mathrm{Cy}_{3} \mathrm{P}-\mathrm{NPO}-\mathrm{B}\left(\mathrm{C}_{6} \mathrm{~F}_{5}\right)_{3}$. Bottom: Molecular structures of $\mathrm{Cy}_{3} \mathrm{P}=\mathrm{NP}(\mathrm{O}) \mathbf{A}$, $\mathrm{Cy}_{3} \mathrm{P}-\mathrm{NP}(\mathrm{A}) \mathrm{O}-\mathrm{B}\left(\mathrm{C}_{6} \mathrm{~F}_{5}\right)_{3}$ and $\mathrm{Cy}_{3} \mathrm{P}-\mathrm{NPO}-\mathrm{B}\left(\mathrm{C}_{6} \mathrm{~F}_{5}\right)_{3}$ with thermal ellipsoids shown at the $50 \%$ probability level. Hydrogen atoms are omitted for the sake of clarity. Selected interatomic distances $(\AA)$ and bond angles $\left({ }^{\circ}\right)$ : $\mathbf{A}$ : $\left(\mathrm{Cy}_{3}\right) \mathrm{P}-\mathrm{N}, 1.5765(8) ; \mathrm{N}-\mathrm{P}, 1.5813(9)$ and $\mathrm{P}-\mathrm{O}, 1.4889(8) ;\left(\mathrm{Cy}_{3}\right) \mathrm{P}-\mathrm{N}-\mathrm{P}, 147.62(6)$ and $\mathrm{N}-\mathrm{P}-\mathrm{O}, 119.59(4)$. B: $\left(\mathrm{Cy}_{3}\right) \mathrm{P}-\mathrm{N}, 1.5761(12) ; \mathrm{N}-\mathrm{P}, 1.5465(12) ; \mathrm{P}-\mathrm{O}, 1.5171(10)$ and $\mathrm{O}-\mathrm{B}, 1.5110(18) ;\left(\mathrm{Cy}_{3}\right) \mathrm{P}-\mathrm{N}-\mathrm{P}, 165.17(9) ; \mathrm{N}-\mathrm{P}-$ $\mathrm{O}, 114.43(6)$ and $\mathrm{P}-\mathrm{O}-\mathrm{B}, 148.83(9) ; \mathbf{C}:\left(\mathrm{Cy}_{3}\right) \mathrm{P}-\mathrm{N}, 1.6289(9) ; \mathrm{N}-\mathrm{P}, 1.5555(9) ; \mathrm{P}-\mathrm{O}, 1.5549(8)$ and $\mathrm{O}-\mathrm{B}$, 1.5454(13); (Cy3) P-N-P, 140.18(6); N-P-O, 110.73(4) and $\mathrm{P}-\mathrm{O}-\mathrm{B}, 131.50(6)$.

Schulz and co-workers reported on the Staudinger reactivity ${ }^{37}$ of $\mathrm{S}=\mathrm{P}\left(\mathrm{N}_{3}\right)_{3}$ with triphenylphosphine $\left(\mathrm{PPh}_{3}\right)$, which led to the single $\left(\mathrm{S}=\mathrm{P}\left(\mathrm{N}_{3}\right)_{2} \mathrm{NPPh}_{3}\right)$ and double $\left(\mathrm{S}=\mathrm{P}\left(\mathrm{N}_{3}\right)\left(\mathrm{NPPh}_{3}\right)_{2}\right)$ but not the triple $\left(\left(\mathrm{S}=\mathrm{P}\left(\mathrm{NPPh}_{3}\right)_{3}\right)\right)$ Staudinger products. ${ }^{38}$ Inspired by this work, we treated $\mathrm{N}_{3} \mathrm{P}(\mathrm{O}) \mathrm{A}$ with $\mathrm{PPh}_{3}$ at room temperature; however, no reaction was observed. This reaction was repeated with the more electron-rich tricyclohexylphosphine $\left(\mathrm{PCy}_{3}\right)$ in diethyl ether and immediate gas evolution and precipitation of the Staudinger reaction product $\mathrm{Cy}_{3} \mathrm{P}=\mathrm{NP}(\mathrm{O}) \mathbf{A}$ was observed (Figure 4 ). The product was isolated by vacuum filtration in $82 \%$ yield (Figure $\mathrm{S} 6-\mathrm{S} 8) . \quad \mathrm{Cy}_{3} \mathrm{P}=\mathrm{NP}(\mathrm{O}) \mathbf{A}$ exhibits two doublets at $\delta 82.9$ and $\delta 32.3\left({ }^{2} J_{\mathrm{PP}}=21.4\right.$ $\mathrm{Hz}$ ) in the ${ }^{31} \mathrm{P}\left\{{ }^{1} \mathrm{H}\right\}$ NMR spectrum (Figure S8). Additionally, $\mathrm{Cy}_{3} \mathrm{P}=\mathrm{NP}(\mathrm{O}) \mathbf{A}$ was characterized in a single crystal X-ray diffraction experiment and the molecular structure is depicted in Figure $4 \mathrm{~A}$.

Considering that nitrous oxide ${ }^{12}$ and many other small molecules have already been reported to form complexes with frustrated Lewis pairs (FLPs), ${ }^{39-40}$ we added tris(pentafluorophenyl)borane $\left(\mathrm{B}\left(\mathrm{C}_{6} \mathrm{~F}_{5}\right)_{3}, \quad \mathrm{BCF}\right)$ to a solution of $\mathrm{Cy}_{3} \mathrm{P}=\mathrm{NP}(\mathrm{O}) \mathrm{A}$ in dichloromethane, leading to new ${ }^{31} \mathrm{P}$ NMR resonances at $\delta 52.5$ and $\delta 32.9\left({ }^{2} J_{\mathrm{PP}}=16.8 \mathrm{~Hz}\right)$ in the ${ }^{31} \mathrm{P}\left\{{ }^{1} \mathrm{H}\right\}$ NMR spectrum (Figure $\mathrm{S} 11$ ). After the reaction mixture stirred for $30 \mathrm{~min}$ at room temperature, all volatile materials were removed under reduced pressure, allowing us to isolate 
$\mathrm{Cy} 3 \mathrm{P}-\mathrm{NP}(\mathbf{A}) \mathrm{O}-\mathrm{B}\left(\mathrm{C}_{6} \mathrm{~F}_{5}\right)_{3}$ as a colorless solid in quantitative yield (Figure S9-S13). An analytical sample was crystallized in diethyl ether and the crystals were analyzed in a X-ray diffraction experiment, leading to the structure depicted in Figure 4B. For the complete complexation of NPO, A can be cleaved off by irradiating $(\lambda=254 \mathrm{~nm})$ a solution of $\mathrm{Cy}_{3} \mathrm{P}-\mathrm{NP}(\mathbf{A}) \mathrm{O}-\mathrm{B}\left(\mathrm{C}_{6} \mathrm{~F}_{5}\right)_{3}$ in benzene or toluene for $220 \mathrm{~min}$. Anthracene photodimerizes during the irradiation and can separated from the reaction mixture by filtration. ${ }^{41}$ The slightly yellow colored filtrate was mixed (in the case of benzene as a solvent) or layered with pentane and placed in the freezer. After three days colorless crystals formed and the crystals were collected by vacuum filtration, washed with pentane and isolated in $42 \%$ yield (Figure S14-S18). When the isolated material was dissolved in chloroform a doublet signal at $\delta 44.1(J=78.2 \mathrm{~Hz})$ for $\mathrm{PCy}_{3}$ and a doublet of quintets signal at $\delta 271.1 \mathrm{ppm}(J=77.4,25.5 \mathrm{~Hz})$ for NPO were observed in the ${ }^{31} \mathrm{P}\left\{{ }^{1} \mathrm{H}\right\}$ NMR spectrum (Figure S16). X-ray diffraction analysis on a single crystal directly grown from a benzene/pentane solution after irradiation reveals the $\mathrm{Cy}_{3} \mathrm{P}-\mathrm{NPO}-\mathrm{B}\left(\mathrm{C}_{6} \mathrm{~F}_{5}\right)_{3}$ structure (Figure $4 \mathrm{C}$ ). The latter splitting originates from through space coupling of phosphorus to fluorine in $\mathrm{B}\left(\mathrm{C}_{6} \mathrm{~F}_{5}\right)_{3}$ as only a doublet signal is observed in the ${ }^{31} \mathrm{P}\left\{{ }^{1} \mathrm{H},{ }^{19} \mathrm{~F}\right\}$ NMR experiment. ${ }^{42}$ The compound is thermally unstable and decomposes after one day at room temperature or by heating over night at $50{ }^{\circ} \mathrm{C}$. In the ${ }^{31} \mathrm{P}\left\{{ }^{1} \mathrm{H}\right\} \mathrm{NMR}$ spectrum, two major doublet signals at $\delta 42.2$ and $\delta 40.7 \mathrm{ppm}$ together with some minor signals at around $\delta-20 \mathrm{ppm}$ were observed that could not be unambiguously assigned (Figure S19).

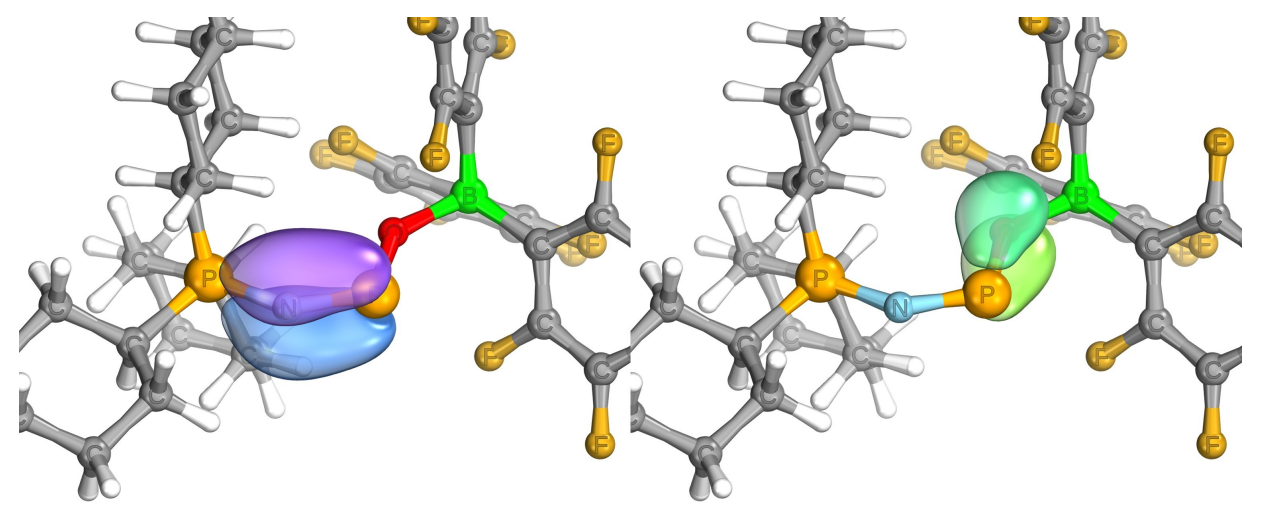

Figure 5: Computed Intrinsic Bond Orbitals (IBOs) of the N-P (left) and P-O (right) $\pi$-bonds based on the geometry of the X-ray structure depicted in Figure 4C at $\omega$ B97M-D3(BJ)/def2-TZVPP.

The interatomic distances in the single crystal for the NPO fragment are almost the same for the N-P (1.5555(9) $\AA$ ) and $\mathrm{P}-\mathrm{O}(1.5549(8) \AA)$ linkages. Intrinsic Bond Orbital (IBO) analysis shows the bonding of the $\pi$ system, where there is visual evidence for both $\mathrm{N}-\mathrm{P}$ and $\mathrm{P}-\mathrm{O} \pi$ bonding (Figure 5). The Wiberg bond order (WBO) for the N-P bond is 1.47 and for the $\mathrm{P}-\mathrm{O}$ bond 1.05. The bond orders are reflective of the high electronegativity of $\mathrm{N}$ and $\mathrm{O}$ and the consequent greater coefficients on $\mathrm{N}$ and $\mathrm{O}$ rather than $\mathrm{P}$ in the $\pi$ system, which acts to bring down the WBO numbers. Hence, the main resonance contributor is the one with the $\mathrm{Cy}_{3} \mathrm{P}^{\oplus}-\mathrm{N}=\mathrm{P}-\mathrm{O}-\mathrm{B}^{\ominus}\left(\mathrm{C}_{6} \mathrm{~F}_{5}\right)_{3}$ bonding pattern, and formal positive and negative charges on the phosphine and borate, respectively. Compounds of the type R-N=P-OR' exhibit a similar bonding pattern, but they are rare and mainly derive from the combination of an alkoxide with the Mes*NP+ cation. ${ }^{43-50}$ Gaseous NPO is predicted to be linear, and has two bonds of almost equal length, a N-P bond distance of $1.4965 \AA$ at the $\operatorname{CCSD}(\mathrm{T}) / \mathrm{CBS}$ level and a $\mathrm{P}-\mathrm{O}$ bond distance of $1.4656 \AA$ at the same level. ${ }^{24}$ Similar to $\mathrm{N}_{2} \mathrm{O}$, the geometry of NPO is bent in its FLP complex. 


\section{Data Availability}

All relevant data generated and analyzed during this study, including crystal structures, NMR, IR, MBMS spectra and optimized coordinates for all calculated compounds, are included in this Article and its Supplementary Information, and are also available from the authors upon reasonable request.

\section{Acknowledgements}

A.K.E. thanks the Alexander von Humboldt foundation for a Feodor Lynen postdoctoral fellowship. This material is based on research supported by the National Science Foundation, under No. CHE-1955612.

\section{Competing financial interests}

None.

\section{Materials \& Correspondence}

Correspondence and material requests should be addressed to C.C.C.

\section{Orcid}

A.K.E. 0000-0003-1029-9272

M.L.Y.R. 0000-0002-0900-3545

P.M. 0000-0001-6530-3852

C.C.C. $0000-0003-2568-3269$

\section{References}

1. Ravishankara, A.; Daniel, J. S.; Portmann, R. W., Nitrous oxide $\left(\mathrm{N}_{2} \mathrm{O}\right)$ : the dominant ozonedepleting substance emitted in the $21^{\text {st }}$ century. Science 2009, 326, 123-125.

2. Severin, K., Synthetic chemistry with nitrous oxide. Chem. Soc. Rev. 2015, 44, 6375-6386.

3. Armor, J. N.; Taube, H., Formation and reactions of $\left[\left(\mathrm{NH}_{3}\right)_{5} \mathrm{RuN}_{2} \mathrm{O}^{2+}\right]$. J. Am. Chem. Soc. 1969, 91, 6874-6876.

4. Bottomley, F.; Brooks, W. V. F., Mode of bonding of dinitrogen oxide (nitrous oxide) in (dinitrogen oxide)pentaammineruthenium. Inorg. Chem. 1977, 16, 501-502.

5. Paulat, F.; Kuschel, T.; Näther, C.; Praneeth, V. K. K.; Sander, O.; Lehnert, N., Spectroscopic Properties and Electronic Structure of Pentammineruthenium(II) Dinitrogen Oxide and Corresponding Nitrosyl Complexes: Binding Mode of $\mathrm{N}_{2} \mathrm{O}$ and Reactivity. Inorg. Chem. 2004, 43, 6979-6994.

6. Pamplin, C. B.; Ma, E. S. F.; Safari, N.; Rettig, S. J.; James, B. R., The Nitrous Oxide Complex, $\mathrm{RuCl}_{2}\left(\eta^{1}-\mathrm{N}_{2} \mathrm{O}\right)(\mathrm{P}-\mathrm{N})\left(\mathrm{PPh}_{3}\right)(\mathrm{P}-\mathrm{N}=[o-(N, N$-Dimethylamino $)$ phenyl $]$ diphenylphosphine $)$; Low Temperature Conversion of $\mathrm{N}_{2} \mathrm{O}$ to $\mathrm{N}_{2}$ and $\mathrm{O}_{2}$. J. Am. Chem. Soc. 2001, 123, 8596-8597.

7. Piro, N. A.; Lichterman, M. F.; Harman, W. H.; Chang, C. J., A Structurally Characterized Nitrous Oxide Complex of Vanadium. J. Am. Chem. Soc. 2011, 133, 2108-2111.

8. Gyton, M. R.; Leforestier, B.; Chaplin, A. B., Rhodium(I) Pincer Complexes of Nitrous Oxide. Angew. Chem. Int. Ed. 2019, 58, 15295-15298. 
9. Zhuravlev, V.; Malinowski, P. J., A Stable Crystalline Copper(I)- $\mathrm{N}_{2} \mathrm{O}$ Complex Stabilized as the Salt of a Weakly Coordinating Anion. Angew. Chem. Int. Ed. 2018, 57, 11697-11700.

10. Mokhtarzadeh, C. C.; Chan, C.; Moore, C. E.; Rheingold, A. L.; Figueroa, J. S., Side-On Coordination of Nitrous Oxide to a Mononuclear Cobalt Center. J. Am. Chem. Soc. 2019, 141, 15003-15007.

11. Puerta Lombardi, B. M.; Gendy, C.; Gelfand, B. S.; Bernard, G. M.; Wasylishen, R. E.; Tuononen, H. M.; Roesler, R., Side-on Coordination in Isostructural Nitrous Oxide and Carbon Dioxide Complexes of Nickel. Angew. Chem. Int. Ed. 2021, 60, 7077-7081.

12. Otten, E.; Neu, R. C.; Stephan, D. W., Complexation of Nitrous Oxide by Frustrated Lewis Pairs. J. Am. Chem. Soc. 2009, 131, 9918-9919.

13. Tskhovrebov, A. G.; Solari, E.; Wodrich, M. D.; Scopelliti, R.; Severin, K., Covalent Capture of Nitrous Oxide by N-Heterocyclic Carbenes. Angew. Chem. Int. Ed. 2012, 51, 232-234.

14. Tskhovrebov, A. G.; Vuichoud, B.; Solari, E.; Scopelliti, R.; Severin, K., Adducts of Nitrous Oxide and N-Heterocyclic Carbenes: Syntheses, Structures, and Reactivity. J. Am. Chem. Soc. 2013, 135, 9486-9492.

15. Dillon, K. B.; Platt, A. W. G.; Waddington, T. C., The identification of some new azidoderivatives of phosphorus. Inorg. Nucl. Chem. Letters 1978, 14, 511-513.

16. Buder, W.; Schmidt, A., Phosphorazide und deren Schwingungsspektren. Z. Anorg. Allg. Chem. 1975, 415, 263-267.

17. Zeng, X.; Bernhardt, E.; Beckers, H.; Willner, H., Synthesis and Characterization of the Phosphorus Triazides $\mathrm{OP}\left(\mathrm{N}_{3}\right)_{3}$ and $\mathrm{SP}\left(\mathrm{N}_{3}\right)_{3}$. Inorg. Chem. 2011, 50, 11235-11241.

18. Zeng, X.; Beckers, H.; Willner, H., Elusive $\mathrm{O}=\mathrm{P} \equiv \mathrm{N}$, a Rare Example of Phosphorus $\sigma^{2} \lambda^{5}$ Coordination. J. Am. Chem. Soc. 2011, 133, 20696-20699.

19. Wu, Z.; Song, C.; Liu, J.; Lu, B.; Lu, Y.; Trabelsi, T.; Francisco, J. S.; Zeng, X., Photochemistry of OPN: Formation of Cyclic PON and Reversible Combination with Carbon Monoxide. Chem. Eur. J. 2018, 24, 14627-14630.

20. Ahlrichs, R.; Schunck, S.; Schnöckel, H., Structure of Molecular PNO, Matrix Isolation and ab initio Calculations. Angew. Chem. Int. Ed. 1988, 27, 421-423.

21. Bell, I. S.; Hamilton, P. A.; Davies, P. B., Detection of the transient PNO molecule by infrared laser absorption spectroscopy. Mol. Phys. 1998, 94, 685-691.

22. Okabayashi, T.; Yamazaki, E.; Tanimoto, M., Microwave spectrum and molecular structure of PNO. J. Chem. Phys. 1999, 111, 3012-3017.

23. Turner, W. E.; Agarwal, J.; Schaefer, H. F., Structures, Bonding, and Energetics of Potential Triatomic Circumstellar Molecules Containing Group 15 and 16 Elements. J. Phys. Chem. A 2015, 119, 11693-11700.

24. Grant, D. J.; Dixon, D. A.; Kemeny, A. E.; Francisco, J. S., Structures and heats of formation of the neutral and ionic PNO, NOP, and NPO systems from electronic structure calculations. $J$. Chem. Phys. 2008, 128, 164305.

25. Himmel, H.-J.; Linti, G., OPN and SPN: Small Molecules with Great Potential. Angew. Chem. Int. Ed. 2012, 51, 5541-5542.

26. Zeng, X.; Beckers, H.; Willner, H.; Francisco, J. S., Experimental Observation of the 16-Electron Molecules SPN, SNP, and Cyclic PSN. Angew. Chem. Int. Ed. 2012, 51, 3334-3339.

27. Zeng, X.; Li, H.; Sun, H.; Beckers, H.; Willner, H.; Schaefer Iii, H. F., $\mathrm{SN}_{2} \mathrm{P}_{2}$ : A Neutral FiveMembered Sulfur-Pnictogen(III) Ring. Angew. Chem. Int. Ed. 2015, 54, 1327-1330.

28. Tessier, F.; Navrotsky, A.; Le Sauze, A.; Marchand, R., Thermochemistry of Phosphorus Oxynitrides: PON and LiNaPON Glasses. Chem. Mater. 2000, 12, 148-154.

29. Ziurys, L., Detection of interstellar PN-the first phosphorus-bearing species observed in molecular clouds. Astrophys. J. 1987, 321, L81-L85.

30. Turner, B.; Bally, J., Detection of interstellar PN-The first identified phosphorus compound in the interstellar medium. Astrophys. J. 1987, 321, L75-L79.

31. Velian, A.; Cummins, C. C., Facile Synthesis of Dibenzo- $7 \lambda^{3}$-phosphanorbornadiene Derivatives Using Magnesium Anthracene. J. Am. Chem. Soc. 2012, 134, 13978-13981.

32. Velian, A.; Nava, M.; Temprado, M.; Zhou, Y.; Field, R. W.; Cummins, C. C., A Retro DielsAlder Route to Diphosphorus Chemistry: Molecular Precursor Synthesis, Kinetics of $\mathrm{P}_{2}$ Transfer to 1,3-Dienes, and Detection of $\mathrm{P}_{2}$ by Molecular Beam Mass Spectrometry. J. Am. Chem. Soc. 2014, 136, 13586-13589. 
33. Transue, W. J.; Velian, A.; Nava, M.; Martin-Drumel, M.-A.; Womack, C. C.; Jiang, J.; Hou, G.L.; Wang, X.-B.; McCarthy, M. C.; Field, R. W.; Cummins, C. C., A Molecular Precursor to Phosphaethyne and Its Application in Synthesis of the Aromatic 1,2,3,4-Phosphatriazolate Anion. J. Am. Chem. Soc. 2016, 138, 6731-6734.

34. Transue, W. J.; Nava, M.; Terban, M. W.; Yang, J.; Greenberg, M. W.; Wu, G.; Foreman, E. S.; Mustoe, C. L.; Kennepohl, P.; Owen, J. S.; Billinge, S. J. L.; Kulik, H. J.; Cummins, C. C., Anthracene as a Launchpad for a Phosphinidene Sulfide and for Generation of a PhosphorusSulfur Material Having the Composition $\mathrm{P}_{2} \mathrm{~S}$, a Vulcanized Red Phosphorus That Is Yellow. $J$. Am. Chem. Soc. 2019, 141, 431-440.

35. Eckhardt, A. K.; Riu, M.-L. Y.; Müller, P.; Cummins, C. C., Taming Phosphorus Mononitride (PN). Preprint on ChemRxiV 2021, doi:10.33774/chemrxiv-32021-zxtmf.

36. Palluccio, T. D.; Rybak-Akimova, E. V.; Majumdar, S.; Cai, X.; Chui, M.; Temprado, M.; Silvia, J. S.; Cozzolino, A. F.; Tofan, D.; Velian, A.; Cummins, C. C.; Captain, B.; Hoff, C. D., Thermodynamic and Kinetic Study of Cleavage of the $\mathrm{N}-\mathrm{O}$ Bond of N-Oxides by a Vanadium(III) Complex: Enhanced Oxygen Atom Transfer Reaction Rates for Adducts of Nitrous Oxide and Mesityl Nitrile Oxide. J. Am. Chem. Soc. 2013, 135, 11357-11372.

37. Staudinger, H.; Meyer, J., Über neue organische Phosphorverbindungen III. Phosphinmethylenderivate und Phosphinimine. Helv. Chim. Acta 1919, 2, 635-646.

38. Götz, N.; Herler, S.; Mayer, P.; Schulz, A.; Villinger, A.; Weigand, J. J., On the Staudinger Reaction of $\mathrm{SP}\left(\mathrm{N}_{3}\right)_{3}$ with $\mathrm{PPh}_{3}$ and $\left(\mathrm{Me}_{3} \mathrm{Si}\right)_{2} \mathrm{~N}-\left(\mathrm{Me}_{3} \mathrm{Si}\right) \mathrm{N}-\mathrm{PPh}_{2}$. Eur. J. Inorg. Chem. 2006, 2006, 2051-2057.

39. Stephan, D. W.; Erker, G., Frustrated Lewis Pair Chemistry: Development and Perspectives. Angew. Chem. Int. Ed. 2015, 54, 6400-6441.

40. Jupp, A. R.; Stephan, D. W., New Directions for Frustrated Lewis Pair Chemistry. Trends Chem. 2019, 1, 35-48.

41. Bouas-Laurent, H.; Castellan, A.; Desvergne, J.-P.; Lapouyade, R., Photodimerization of anthracenes in fluid solution: structural aspects. Chem. Soc. Rev. 2000, 29, 43-55.

42. Beckett, M. A.; Tebby, J. C.; Thompson, J. J.; Williams, B. J.; Withington, S. C., Phosphorus-31 Fluorine-19 N.M.R. Through-Space Coupling. Phosphorus Sulfur Silicon Relat. Elem. 1990, 51, 277-277.

43. Chernega, A. I.; Antipin, M. Y.; Struchkov, Y. T.; Ruban, A. V.; Romanenko, V. D., The structure of organophosphorus compounds. Part XLIV. The molecular structure of the 2methylphenyl ester of $N$-[2, 4, 6-tri(tert-butyl) phenyl] imidophosphenous acid. J. Struct. Chem. 1990, 31, 301-306.

44. Niecke, E.; Detsch, R.; Nieger, M.; Reichert, F.; Schoeller, W., From covalent to ionic bonding: spontaneous bond dissociation in oxy-substituted iminophosphanes. Bull. Soc. Chim. Fr. 1993, 130, 25-31.

45. Pötschke, N.; Nieger, M.; Niecke, E., Crystal Structure of 1,1,1,3,3,3-Hexafluoro-2-propanyloxy(2,4,6-tri-tert-butylphenylimino)phosphine. Acta Chem. Scand. 1997, 51, 337-339.

46. Kuprat, M.; Kuzora, R.; Lehmann, M.; Schulz, A.; Villinger, A.; Wustrack, R., Silver tetrakis(hexafluoroisopropoxy)aluminate as hexafluoroisopropyl transfer reagent for the chlorine/hexafluoroisopropyl exchange in imino phosphanes. J. Organomet. Chem. 2010, 695, 1006-1011.

47. Chernega, A. N.; Antipin, M. Y.; Struchkov, Y. T.; Ruban, A. V.; Romanenko, V. D., Structure of organophosphorus compounds. Part XLII. The molecular structure of the 2,6-di-tert-butyl-4methylphenyl ester of $N$-[2,4,6-tri(tert-butyl)-phenyl]phosphenimidous acid. J. Struct. Chem. 1989, 30, 957-962.

48. Chernega, A. N.; Rusanov, É. B.; Ruban, A. V.; Romanenko, V. D., Molecular structure of $\sigma^{3} \lambda^{5}$. J. Struct. Chem. 1991, 32, 718-728.

49. Pötschke, N.; Barion, D.; Nieger, M.; Niecke, E., Chirale Iminophosphane durch Reaktion von Lithiumalkoholaten mit Chlor-(2,4,6-tri-tert.-butylphenylimino)phosphan. Tetrahedron 1995, 51, 8993-8996.

50. Chernega, A. N.; Romanenko, V. D., Molecular structure of the (-)menthyl ester of N-(2,4,6-tritert-butylphenyl)imidophosphinous acid. J. Struct. Chem. 1996, 37, 364-366. 
TOC:

FLP Stabilized NPO

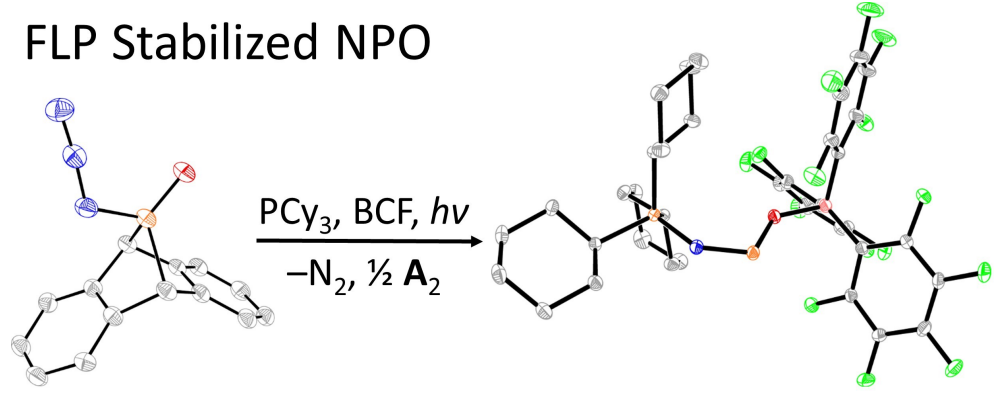

10 